\title{
Multi-gas scenarios to stabilize radiative forcing
}

\author{
Detlef P. van Vuuren ${ }^{\mathrm{a}, *}$, John Weyant ${ }^{\mathrm{b}}$, Francisco de la Chesnaye ${ }^{\mathrm{c}}$ \\ a MNP-Netherlands Environment Assessment Agency, Bilthoven, The Netherlands \\ b Stanford University, Stanford, USA \\ ${ }^{\mathrm{c}}$ U.S. Environmental Protection Agency, Washington, DC, USA
}

Received 6 April 2005; received in revised form 15 October 2005; accepted 17 October 2005

Available online 7 December 2005

\begin{abstract}
Using the results of a recent model comparison study performed by the Energy Modeling Forum, we have shown in this paper that including non- $\mathrm{CO}_{2}$ gases in mitigation analysis is crucial in the formulation of a cost-effective response. In the absence of climate policies, the emissions of non- $\mathrm{CO}_{2}$ greenhouse increase from $2.7 \mathrm{GtC}$-eq/year in 2000 to $5.1 \mathrm{GtC}$-eq/year in 2100 (averaged across all the models). A multi-gas reduction strategy stabilizing radiative forcing at $4.5 \mathrm{~W} / \mathrm{m}^{2}$ (compared to pre-industrial) reduces the emissions (on average) to $2.5 \mathrm{GtC}$-eq. Such an approach leads to a cost reduction of 30-40\% compared to a $\mathrm{CO}_{2}$ only reduction strategy for the same target. The choices of a target and how the gases are valued form an essential part of developing multi-gas strategies. Model results show that using IPCC global warming potentials (GWPs) as basis for substitution has large consequences for the timing of methane reductions. In this context, further research and assessment on multi-gas metrics, going beyond the mere physical aspects, are important for both research and policy-making.

(C) 2005 Elsevier B.V. All rights reserved.
\end{abstract}

JEL classification: Q-54

Keywords: Model comparison; Mitigation scenarios; Climate change; Non- $\mathrm{CO}_{2}$ gases; Stabilization scenarios

\section{Introduction}

Of the set of gases that contribute to the enhanced greenhouse effect, carbon dioxide provides the largest contribution. Nevertheless, taken collectively, the non- $\mathrm{CO}_{2}$ greenhouse gases contribute about $25 \%$ of current greenhouse gas emissions (in terms of equivalent emissions,

\footnotetext{
* Corresponding author. RIVM, P.O. Box 1, 3720 BA Bilthoven, The Netherlands. Tel.: +31 30 2742046; fax: +31 30 2744464.

E-mail address: detlef.van.vuuren@rivm.nl (D.P. van Vuuren).
} 
using IPCC 100-year global warming potentials, GWPs; non- $\mathrm{CO}_{2}$ greenhouse gases (NCGGs) comprise $\mathrm{CH}_{4}, \mathrm{~N}_{2} \mathrm{O}, \mathrm{PFCs}$, $\mathrm{HFCs}$ and $\mathrm{SF}_{6}$ ). Despite this still appreciable contribution from NCGGs, most literature on mitigation scenarios has concentrated on $\mathrm{CO}_{2}$. One reason for the limited number of so-called 'multi-gas studies' is that consistent information on emission reduction costs for the NCGGs gases has been lacking. Over the last few years, the number of studies that consider NCGGs as well as $\mathrm{CO}_{2}$ abatement potential have been increasing. Such studies generally find that major cost reductions can be obtained through: (1) relatively cheap abatement options for some of the NCGGs (USEPA, 1999; Blok et al., 2001) and (2) an increase in flexibility in abatement options (Hayhoe et al., 1999; Reilly et al., 1999; Tol, 1999; Jensen and Thelle, 2001; Manne and Richels, 2001; Van Vuuren et al., 2003). Other studies report additional advantages of multi-gas strategies, such as in avoiding climate impacts by focusing on shortlived gases (Hansen et al., 2000). Interestingly, policy-makers have already acknowledged the potential benefits of a multi-gas approach by formulating the Kyoto Protocol targets and the U.S. Administration GHG intensity strategy in terms of a 'basket' or aggregation of greenhouse gases, thereby allowing substitution among these gases.

For ' $\mathrm{CO}_{2}$-only' stabilization, there is a large range of studies that allows for a reasonable understanding of mitigation potential and the associated range of costs across a wide spectrum of climate targets based on a wide range of assumptions and modeling approaches (see Hourcade and Shukla, 2001). A similar situation has not existed for multi-gas stabilization, as the number of individual studies that could be assessed has been rather limited; furthermore, methodologies have not been compared and studies have generally not assessed multiple stabilization targets. A large model comparison study and the data that has recently been collected on marginal abatement costs for NCGGs provide an opportunity to improve that situation. The study was conducted under Stanford University's Energy Modeling Forum (EMF-21; see (EMF, 2005; Weyant et al., 2005)).

In this paper, we use the results of the EMF-21 scenarios to develop insights into the question of how multi-gas climate change mitigation strategies differ from ' $\mathrm{CO}_{2}$-only' mitigation strategies. ${ }^{1}$ We also compare these new multi-gas scenarios to the baseline scenarios employed earlier by IPCC in the Third Assessment Report (the SRES scenarios) (Nakicenovic et al., 2000) and compare the results of the different modeling groups. Finally, we use the results to discuss some crucial methodological issues with regard to multi-gas reduction strategies. In order to evaluate the trade-offs of reducing one gas versus another, the climate impacts of each of the various gases and their associated reduction costs need to be made comparable. As shown in this paper, the choice of such metrics is far from straightforward and can crucially change the resulting 'optimal' reduction strategy.

Section 2 provides an introduction into the methodological questions that are addressed in this paper, while Section 3 discusses the results for the scenarios without climate policy. Section 4 discusses the results for the mitigation scenarios. These results form the basis of a broader discussion in Section 5 on the metrics of multi-gas mitigation scenarios. Finally, conclusions are drawn in Section 6.

\section{Methodological questions in multi-gas analysis}

The main source of information used in this paper comes from the EMF-21 study on multigas scenarios. In EMF-21, 18 modeling groups and 8 expert organizations on mitigation options

\footnotetext{
${ }^{1}$ The authors acknowledge the contribution of the modeling teams, who provided input for the EMF-21 study. This input serves as the basis for analysis in this paper.
} 
Table 1

Key characteristics of EMF 21 models

\begin{tabular}{|c|c|c|c|c|c|c|}
\hline Model & $\begin{array}{l}\text { Model } \\
\text { type (a) }\end{array}$ & $\begin{array}{l}\text { Representation of } \\
\text { NCGG emission } \\
\text { reduction options (b) }\end{array}$ & $\begin{array}{l}\text { NCGG contribution } \\
\text { method (c) }\end{array}$ & $\begin{array}{l}\text { Solution } \\
\text { concept (d) }\end{array}$ & $\begin{array}{l}\text { Time } \\
\text { horizon (e) }\end{array}$ & $\begin{array}{l}\text { Group } \\
\text { in this } \\
\text { paper (f) }\end{array}$ \\
\hline AMIGA & MSGE & RFPF & GWPs & $\mathrm{RD}$ & 2100 & 1 \\
\hline GTEM & MSGE & RFPF & GWPs & $\mathrm{RD}$ & 2030 & 1 \\
\hline GEMINI-E3 & MSGE & RFPF & GWPs & $\mathrm{RD}$ & 2050 & 1 \\
\hline EU-PACE & MSGE & RFPF & GWPs & $\mathrm{RD}$ & & 1 \\
\hline EDGE & MSGE & RFPF & GWPs & $\mathrm{RD}$ & 2030 & 1 \\
\hline EPPA & MSGE & RFPF & GWPs & $\mathrm{RD}$ & 2100 & 1 \\
\hline IPAC & MSGE & RFPF & GWPs & $\mathrm{RD}$ & 2100 & 1 \\
\hline SGM & MSGE & RFPF & GWPs & $\mathrm{RD}$ & 2050 & 1 \\
\hline WIAGEM & MSGE & RFPF & GWPs & $\mathrm{RD}$ & 2100 & 1 \\
\hline Combat & AGE & RFM & $\mathrm{RF}$ & INTOP & 2100 & 2 \\
\hline FUND & AGE & RFM & $\mathrm{RF}$ & INTOP & 2100 & 2 \\
\hline MERGE & AGE & RFM & $\mathrm{RF}$ & INTOP & 2100 & 2 \\
\hline GRAPE & AGE & SM & $\mathrm{RF}$ & INTOP & 2100 & 2 \\
\hline IMAGE & $\mathrm{ISM}^{\mathrm{a}}$ & SM & GWPs & $\mathrm{RD}$ & 2100 & 3 \\
\hline MESSAGE & ISM & SM-2 & GWPs & $\mathrm{RD}$ & 2100 & 3 \\
\hline AIM & ISM & SM-2 & GWPs & $\mathrm{RD}$ & 2100 & 3 \\
\hline MiniCAM & ISM & SM-2 & GWPs & $\mathrm{RD}$ & 2100 & 3 \\
\hline POLES/AgriPol & ISM & SM & GWPs & $\mathrm{RD}$ & 2030 & 3 \\
\hline
\end{tabular}

$\mathrm{NCGG}-$ non- $\mathrm{CO}_{2}$ GHG gases.

(a) MSGE-Multi-Sector General Equilibrium; AGE-Aggregate Gen Equilibrium; ISM-Integrated Structural Model.

(b) RFPF—Reduced Form Adjustment to Production Functions; RFM—Red Form MACs; SM-Structural Models; SM-

2 indicates models that have included individual reduction measures.

(c) RF-Radiative Forcing; GWPs - Global Warming Potentials.

(d) RD_Recursive Dynamic; INTOP_-Inter-temporal Optimization.

(e) Groups only refer to the colour coding used in the figures.

a The term Integrated Structural Model (ISM) is used here to indicate the group of models that include relatively detailed structural models of the sectors that emit non- $\mathrm{CO}_{2}$ greenhouse gases. Most of the models in this group can also be classified as Integrated Assessment Models.

collaborated in improving the current state of multi-gas modeling. The purpose of the exercise was twofold: first, to perform a comprehensive assessment of modeling work to improve the understanding of including NCGGs and terrestrial carbon sequestration (sinks) into short- and long-term mitigation policies, and second, to strengthen the collaboration between experts on NCGG, and sinks abatement options and modeling groups. The second purpose was felt necessary, as many groups had no representation of NCGG emissions or abatement at the beginning of the exercise. Table 1 provides a summary listing of the models and characteristics. Four main model categories can be identified for those participating in the EMF-21 study: MultiSector General Equilibrium models (MSGE), Aggregate General Equilibrium models (AGE), Integrated Structural Models (ISM) and Market Equilibrium models (ME). ${ }^{2}$ Within these categories similar techniques are often used to include the non- $\mathrm{CO}_{2}$ gases (see Table 1).

Given the body of knowledge on $\mathrm{CO}_{2}$ abatement, a crucial question is how our insights will have to change if multi-gas strategies are to be adopted. Models that are able to address such

\footnotetext{
${ }^{2}$ The term Integrated Structural Model (ISM) is used here for the group of models that include relatively detailed structural models of the sectors that emit non- $\mathrm{CO}_{2}$ greenhouse gases. Most of the models in this group can also be classified as Integrated Assessment Models.
} 
questions need to be able to deal with a set of rather obvious questions directly related to modeling NCGGs:

a. What activities cause emissions of NCGGs and how are these activities represented in the models?

b. What is the mitigation potential of different sources of NCGGs and how can this information be included in the models?

c. How do implementation barriers influence the abatement potential that can be implemented at any point of time?

d. How will the abatement potential for NCGGs evolve over time; and be influenced by technological change and/or reductions of implementation barriers?

In the EMF-21 study, the first question was addressed by developing a dataset of current NCGG emissions in different regions - and indicating their main economic driving forces. The way models include this information depends strongly on the type of model being considered. Detailed integrated assessment models generally couple emissions of NCGGs to activities explicitly included in the models (e.g. the number of farm animals maintained). General equilibrium models, in contrast, usually include these gases by incorporating them in the production function of the model. To help answer the second question, this NCGG dataset was extended by including a set of abatement options that could be identified for 2000-2020. Information on these abatement options was made available in terms of the characteristics of individual measures, but also in the form of so-called marginal abatement curves (MACs). Again, the way models adopted this information differed, depending mostly on the type of model (including a description of individual reduction measures, use of MACs, or incorporating the information into the production functions). The last two questions were left mainly to the individual modeling groups to address. For recent work on the question how potential can evolve over time, see Graus et al. (2004) and Delhotal and Gallaher (in press).

In addition to the set of questions raised above, a second set of questions is needed to address multi-gas abatement strategies, which originate from the need to combine the contributions of the different gases, with different lifetimes, and different radiative properties. This second set of issues is also directly relevant to policy-making:

1. How to define a mitigation target for a multi-gas stabilization scenario?

2. How to allow for substitution among the different greenhouse gases; which metric is used to determine the value of each gas?

Regarding the first question, the modeling teams in EMF-21 decided, as a group, that the appropriate target for a multi-gas, mitigation exercise would be radiative forcing as (1) it was best comparable to the concentration targets used earlier in $\mathrm{CO}_{2}$-only studies, while (2) allowing for substitution among different gases. In quantitative terms, the group decided to compare model runs that focused on stabilizing radiative forcing at $4.5 \mathrm{~W} / \mathrm{m}^{2}$ above pre-industrial levels. A radiative forcing target of $4.5 \mathrm{~W} / \mathrm{m}^{2}$ is more or less equal to a $\mathrm{CO}_{2}$ concentration at $550 \mathrm{ppmv}$ (the standard case in most earlier work), assuming $1 \mathrm{~W} / \mathrm{m}^{2}$ additional forcing for the NCGGs (Wigley and Raper, 2001). For reference, a $4.5 \mathrm{~W} / \mathrm{m}^{2}$ target also roughly corresponds to a $3{ }^{\circ} \mathrm{C}$ equilibrium temperature increase relative to pre-industrial times using a medium climate sensitivity. With respect to the second question (how to define substitution among gases over 
time) this was again left to the individual modeling groups to address. As Table 1 shows, two main methods were used, substitution based on the 100-year GWPs of the different gases and substitution based on inter-temporal optimization under the radiative forcing target. In both cases, the time horizon plays an important role. In the former case, alternatives of 30 or 500 year GWPs give different results; in the latter, results critically depend on the optimization year chosen (here 2100-2150). The common practice is to compare and aggregate emissions by using GWPs. Emissions of NCGGs are converted to a carbon dioxide equivalent basis using GWPs. GWPs used here are calculated over a 100-year period, and vary due to both the gases' ability to trap heat and their atmospheric lifetime compared to an equivalent mass of $\mathrm{CO}_{2}{ }^{3}$ We return to the question of stabilization and substitution metrics (GWPs) in Section 5 with reference to the modeling results.

Based on all considerations above, three main scenarios were run in each model:

1. a reference scenario without climate policy, based on the preferences of individual modeling teams;

2. a scenario that aims to stabilize radiative forcing at $4.5 \mathrm{~W} / \mathrm{m}^{2}$ (above pre-industrial) using a $\mathrm{CO}_{2}$-only strategy and,

3. a scenario that aims to stabilize radiative forcing at $4.5 \mathrm{~W} / \mathrm{m}^{2}$ (above pre-industrial) using a full multi-gas strategy.

The first scenario aimed to give insight into NCGG emissions in the absence of climate policies. The second and third scenarios, taken together, aimed to give insight in the potential role of non- $\mathrm{CO}_{2}$ gases in mitigation under a long-term stabilization target (and the methodological questions raised above). It should be noted that in both 2 and 3, no weight is given to short-term benefits of mitigation, which critically influences results. Formally, the EMF21 exercise also included a scenario in which a maximum rate of temperature change target was selected. However, too few models run this scenario to allow comparison of results.

\section{Development of emissions without climate policies}

All modeling groups provided a reference scenario including projections of the emissions of the major greenhouse gases in the absence of climate policy. Fig. 1 shows the pathways for GDP included in the baseline, while Table 2 and Fig. 2 show the results for these reference cases for the emissions of four main categories of gases.

GDP (Fig. 1) grows on average (across all models) by a factor 3.6 in the 2000-2050 period (2.6\% annually) and 9.4 in the $2000-2100$ period ( $2.2 \%$ annually). The spread across the models is considerable - with one model indicating a fivefold increase of GDP until 2100 and another model a 20-fold increase. The MSGE as a group seems to show a somewhat higher GDP growth rate than the ISM and AGE group.

$\mathrm{CO}_{2}$ emissions (Fig. 2) are projected to increase in all models compared to 2000, but the spread in model results is considerable, from 14 to $36 \mathrm{GtC} /$ year in 2100 . On average (across the long-term models), $\mathrm{CO}_{2}$ emissions increase by $1.1 \%$ per year during the 21 st century

\footnotetext{
${ }^{3}$ Although the GWPs have been updated by the IPCC in the Third Assessment Report, estimates of emissions in EMF21 use the GWPs from the Second Assessment Report, in order to be consistent with international reporting standards under the United Nations Framework Convention on Climate Change.
} 


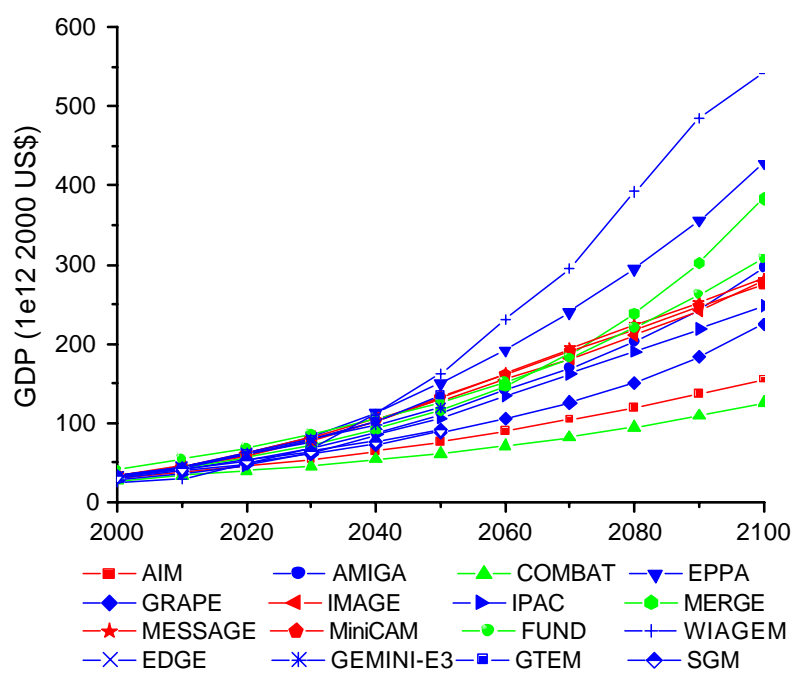

Fig. 1. GDP trajectories in the EMF-21 scenarios.

(results range from $0.8 \%$ to $1.3 \%$ growth annually within one standard deviation). A considerable part of the spread originates in the second part of the century where some models show sustained emissions growth-while others show emission growth slowing down or even going negative (mostly due to assumptions on a stabilizing or declining global population). The substantially slower (or even negative) emission growth rate in the second half of the century occurs in most of the models included in the ISM and MSGE group. The AGE group, on average, seems to have higher $\mathrm{CO}_{2}$ emission growth rates than the other models in this period.

The projected increase in $\mathrm{CH}_{4}$ emissions is considerably less than that for $\mathrm{CO}_{2}$ for most models. Averaged across the different models, the annual emission increase amounts to $0.6 \%$ per year, leading to a decline of the $\mathrm{CH}_{4}$ share in total emissions from $19 \%$ to $13 \%$. The main reason for the slower growth of $\mathrm{CH}_{4}$ compared to the $\mathrm{CO}_{2}$ growth is that emissions mostly originate

Table 2

Results (in GtC-eq.) for reference scenarios averaged across the long-term models ${ }^{\mathrm{a}}$

\begin{tabular}{|c|c|c|c|c|c|c|c|c|c|c|c|}
\hline & \multicolumn{4}{|l|}{2000} & \multicolumn{4}{|l|}{2100} & \multicolumn{3}{|c|}{ Growth rate } \\
\hline & Mean & $-\mathrm{SD}$ & $+\mathrm{SD}$ & $\begin{array}{l}\text { Contribution } \\
\text { (Mean) }(\%)\end{array}$ & Mean & $-\mathrm{SD}$ & $+\mathrm{SD}$ & $\begin{array}{l}\text { Contribution } \\
\text { (Mean) }(\%)\end{array}$ & $\begin{array}{l}\text { Avg. } \\
(\%)\end{array}$ & $\begin{array}{l}-\mathrm{SD} \\
(\%)\end{array}$ & $\begin{array}{l}+\mathrm{SD} \\
(\%)\end{array}$ \\
\hline $\mathrm{CO}_{2}$ & 6.61 & 6.33 & 6.89 & 71.2 & 19.47 & 14.68 & 24.26 & 79.1 & 1.1 & 0.8 & 1.3 \\
\hline $\mathrm{CH}_{4}$ & 1.73 & 1.57 & 1.89 & 18.6 & 3.07 & 2.10 & 4.79 & 12.5 & 0.6 & 0.2 & 1.0 \\
\hline $\mathrm{N}_{2} \mathrm{O}$ & 0.83 & 0.68 & 0.97 & 8.9 & 1.23 & 0.87 & 1.86 & 5.0 & 0.4 & 0.0 & 0.8 \\
\hline F-gases & 0.13 & 0.11 & 0.14 & 1.4 & 0.83 & 0.49 & 1.17 & 3.4 & 1.9 & 1.4 & 2.3 \\
\hline Total & 9.29 & 8.69 & 9.89 & & 24.62 & 18.93 & 30.32 & & 1.0 & 0.7 & 1.2 \\
\hline
\end{tabular}

GtCeq-Gigaton Carbon equivalent. SD—Standard deviation. NCGGs are converted using GWPs from the IPCC Second Assessment Report.

a The numbers include most of the long-term models with EMF-21 that have reported results. Two models, however, were not included in the average results reported here and elsewhere in this article, as their results were too different from the other models (in particular unlikely to comply to the $4.5 \mathrm{~W} / \mathrm{m}^{2}$ target). The results of these models are included in the graphs showing the individual results of the models. 

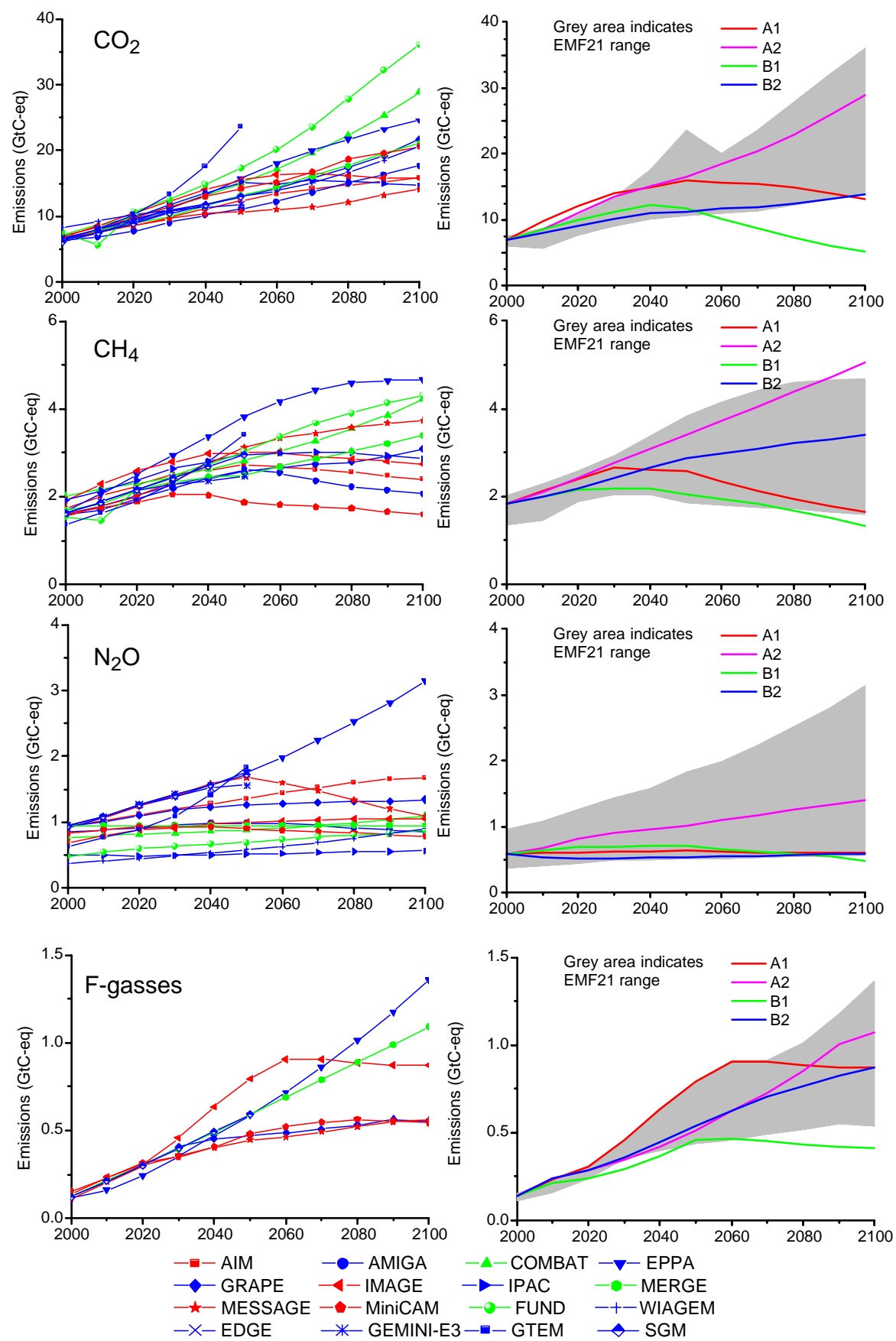

Fig. 2. Baseline emission development in the EMF-21 scenarios (left) and comparison to the SRES scenarios (right).

from the agriculture sector. Activities in this sector are expected to grow slower than the main driver of $\mathrm{CO}_{2}$ emissions energy consumption. Almost all models seem to show signs of stabilizing and declining emissions in the second half of the century, except for those in the AGE 
group. Again, there does not seem to be an obvious reason for this in the dynamics of these models. The range of results for $\mathrm{CH}_{4}$ is somewhat broader than for $\mathrm{CO}_{2}$.

Averaged across all models, emissions of $\mathrm{N}_{2} \mathrm{O}$ are projected to grow $0.4 \%$ annually in the 21 st century (one standard deviation range from 0.0 to $0.8 \%$ ). This is the slowest growth rate of the four groups of gases discussed here, and as a result, the share of $\mathrm{N}_{2} \mathrm{O}$ in total emissions drops from $9 \%$ to $5 \%$. Note that for $\mathrm{N}_{2} \mathrm{O}$, base year emissions of the different models differ substantially. Two factors may contribute to this. First of all, there are different definitions of what should be regarded as human-induced and natural emissions in the case of $\mathrm{N}_{2} \mathrm{O}$ emissions from soils. Secondly, some models may not have included all emission sources.

In the last group, the fluorinated gases (F-gases: PFCs, $\mathrm{HFCs}$ and $\mathrm{SF}_{6}$ ), emissions grow on average faster than $\mathrm{CO}_{2}$ emissions (1.9\% per year). As a result, the contribution of these gases in equivalent emissions increases from $1.4 \%$ to $3.4 \%$, in some models even surpassing $\mathrm{N}_{2} \mathrm{O}$. It should be noted that only a limited subset of models included these gases into the simulations. Most, but not all, of the models project the most rapid increase to occur in the first half of the century.

In conclusion, without climate policies, the baseline scenarios project emissions of NCGGs to grow significantly - but their contribution to 'overall emissions' to drop as growth rates of $\mathrm{CO}_{2}$ are projected to be faster than those for the most important NCGGs. ${ }^{4}$

Fig. 2 also compares the EMF-21 results with the IPCC SRES scenarios (Nakicenovic et al., 2000). In general, the range of the EMF-21 emission projections coincides with those from SRES. Some difference is noted for $\mathrm{CO}_{2}$, where, in the short term, two SRES scenarios are above the EMF-21 range; in the longer term, the B1 is clearly below the SRES range. The latter is caused by the deliberate assumption of radical energy efficiency improvement in $\mathrm{B} 1$. For $\mathrm{N}_{2} \mathrm{O}$, the comparison is slightly complicated by the spread of base year emissions in the EMF-21 set (see discussion above) - but in general, growth rates seem to be similar. The coincidence between the SRES and EMF-21 ranges bears further evaluation. First of all, it should be noted that the ranges in the EMF-21 and SRES study originate from very different causes. In the SRES study, deliberate assumptions to map out possible pathways (storylines) cause emissions to diverge across the different scenarios. In EMF-21, a very similar range results from the use of a multitude of models that were free to choose their own 'modeler's preference' baseline scenario. The correspondence between the EMF-21 and SRES sets of emission projections is also interesting in the light of the comparisons between the SRES set and more recent emission trends. It appears that a much larger set of model projections, completed about 5 years after SRES publication, produced a set of results that is not too divergent from that earlier work. There is some overlap in the models included in the two studies, but the models that were also included in SRES do not represent a majority within the whole EMF-21 set (4 out of the 14 models that reported results) - and do, in fact, very seldom form the EMF-21 range. Of the other modeling groups included, it is very unlikely that simply 'reproducing SRES results' has caused this result, given their independent status, and their methodological differences with most of the SRES models.

The total emission growth under these baseline scenarios implies a sharp increase in radiative forcing as indicated in Fig. 3. Reported increases in radiative forcing projected by the model groups increase from (on average) $1.7 \mathrm{~W} / \mathrm{m}^{2}$ above pre-industrial today to $6-8 \mathrm{~W} / \mathrm{m}^{2}$ in 2100 .

\footnotetext{
${ }^{4}$ For reporting purposes, 'overall emissions' here are calculated as post-calculation on the basis of 100 year GWPs. As indicated in the main text, some of the models do not use GWPs within their model as a basis of substitution while other models do use them.
} 


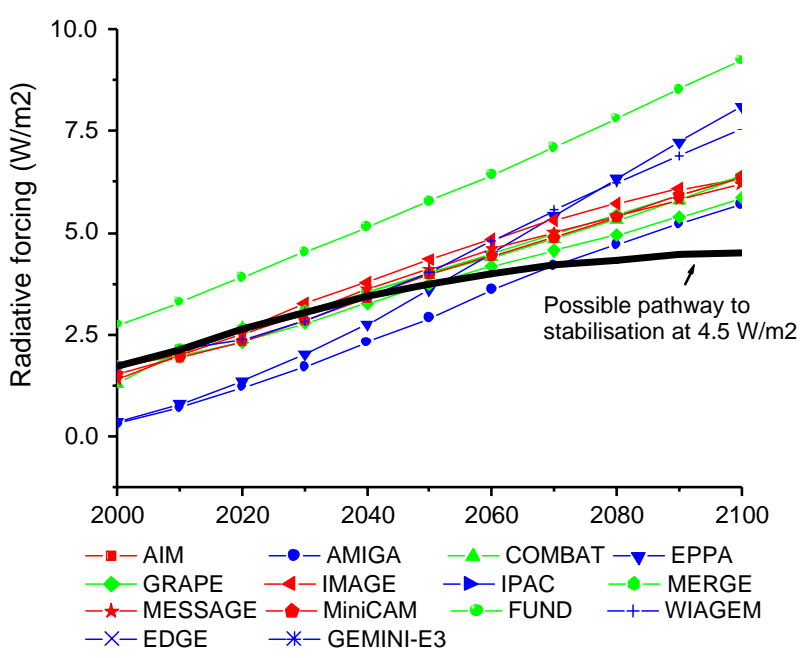

Fig. 3. Increased radiative forcing under the reference scenarios (without climate policies). The thick black line indicates a possible pathway to the stabilization target of $4.5 \mathrm{~W} / \mathrm{m}^{2}$.

This implies that none of the reference scenarios complies with the $4.5 \mathrm{~W} / \mathrm{m}^{2}$ stabilization target without additional policies in place.

\section{Stabilizing radiative forcing at $4.5 \mathrm{~W} / \mathrm{m}^{2}$ : multi-gas versus $\mathrm{CO}_{2}$-only}

\subsection{Emission reductions (total greenhouse gas reductions)}

In order to stabilize greenhouse gas radiative forcing at $4.5 \mathrm{~W} / \mathrm{m}^{2}$ compared to pre-industrial levels, greenhouse gas emissions in the different models need to be reduced substantially in comparison to the baseline emissions. The exact numbers obviously differ depending on the baseline. The average emission pathways, however, including the standard deviation range, are shown in Fig. 4. Averaged across all models, the emission reductions compared to baseline

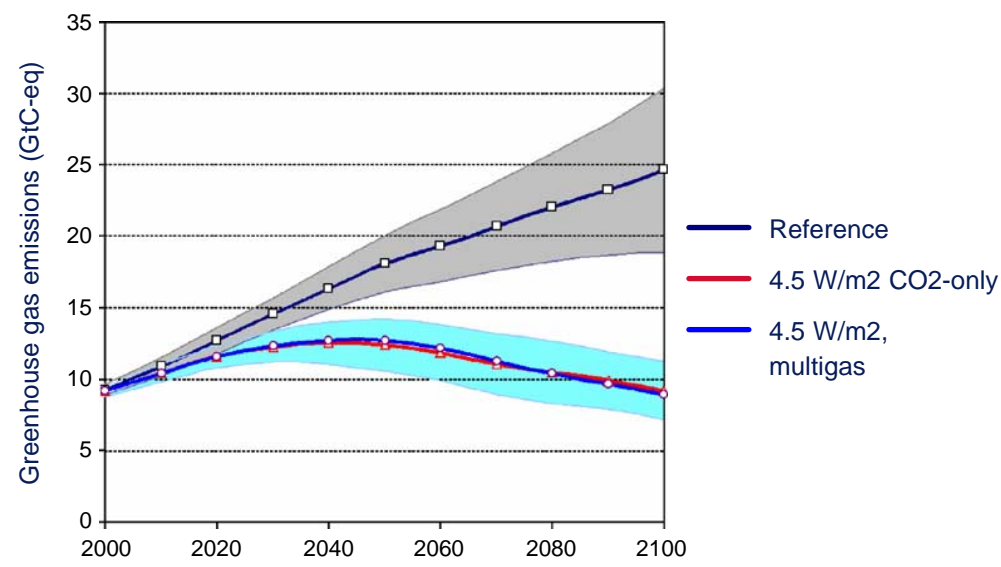

Fig. 4. Total equivalent $\mathrm{CO}_{2}$ emissions under the reference scenarios and the stabilization scenarios. The line indicates mean values across all models, while the shaded area indicates the standard deviation. 
amount to about $10 \%$ in 2020 and to $35 \%$ in 2050 and $65 \%$ in 2100 . There is no significant difference between the total equivalent emission numbers of the multi-gas and $\mathrm{CO}_{2}$-only strategy. As to be expected, the range across the models is reduced somewhat in going from the reference scenario to stabilization scenarios - caused by the (equal) additional constraint set on all models to stabilize radiative forcing.

\subsection{Emission reductions (reductions by gas)}

If we start untangling the contribution of the different gases, one can see that in the $\mathrm{CO}_{2}$-only strategy the largest contribution in mitigation comes from reducing $\mathrm{CO}_{2}$ emissions (by construction). $\mathrm{CO}_{2}$ emissions are reduced by about $75 \%$ in 2100 compared to baseline. Nevertheless, as shown in Fig. 5 and Table 3, a small number of the emission reductions, are, in fact, achieved through reductions in $\mathrm{CH}_{4}$ and $\mathrm{N}_{2} \mathrm{O}$ as systemic changes in the energy system, induced by putting a price on carbon, also reduces these emissions. Emissions of $\mathrm{CH}_{4}$ are reduced by about $20 \%$ and $\mathrm{N}_{2} \mathrm{O}$ by about $10 \%$.

In the multi-gas scenario, a much larger share of the emission reductions occurs through reductions of non- $\mathrm{CO}_{2}$ gases, and as a result smaller reductions of $\mathrm{CO}_{2}$ are required. The emission reduction for $\mathrm{CO}_{2}$ in 2100 drops (on average) as a result from $75 \%$ to $67 \%$. This percentage is still rather high, caused by the large share of $\mathrm{CO}_{2}$ in total emissions (on average, $60 \%$ in 2100) and partly due to exhaustion of reduction options for the NCGGs. The reductions of $\mathrm{CH}_{4}$ across the different models averages around 50\%, with remaining emissions coming from sources for which no reduction options were identified by the experts, such as $\mathrm{CH}_{4}$ emissions from enteric fermentation. For $\mathrm{N}_{2} \mathrm{O}$, the increased reduction in the multi-gas strategy is not as large as for $\mathrm{CH}_{4}$ (almost $40 \%$ ). The main reason is that the identified potential for emission reductions for the main sources of $\mathrm{N}_{2} \mathrm{O}$ emissions, fertilizer use and animal manure, is still limited. Finally, for the F-gases, high reduction rates (about $75 \%$ ) are found across the different models.

Several uncertainties play a role in the differences among the different models. These include the total reduction burden (which depends strongly on projected baseline emissions), the distribution among different sources, the different methodologies used to represent technological change and also the method chosen to determine substitution among the different gases.

It should be noted that although the contributions of different gases change sharply over time, there is considerable spread among the different models. This can be seen in Fig. 5. Many models project relatively early reductions of both $\mathrm{CH}_{4}$ and F-gases under the multi-gas case. However, the subset of models that does not use GWPs as substitution metric for the relative contributions of the different gases to the overall target, but does assume inter-temporal optimization in minimizing abatement costs, does not start to reduce $\mathrm{CH}_{4}$ emissions substantially until the end of the period. The reason for this result is that in aiming at the long-term target, it does not pay to engage in early $\mathrm{CH}_{4}$ emission reductions because $\mathrm{CH}_{4}$ has a short atmospheric life-time (about 10 years). In other words, since the benefits to reducing a radiative forcing in the atmosphere are more immediately felt with $\mathrm{CH}_{4}$ mitigation, these models 'wait' to reduce these emissions as the target approaches. In their calculations, there is not much benefit in reducing $\mathrm{CH}_{4}$ early in the simulation.

In the models that use GWPs as the basis of their substitution, however, $\mathrm{CH}_{4}$ emission reductions are attractive early based on the availability of low cost emission reduction options. It should be noted that for $\mathrm{N}_{2} \mathrm{O}$, reductions in the first decades also seem to be substantial — and here the results do not differ among the different categories of models. This is due to the fact 

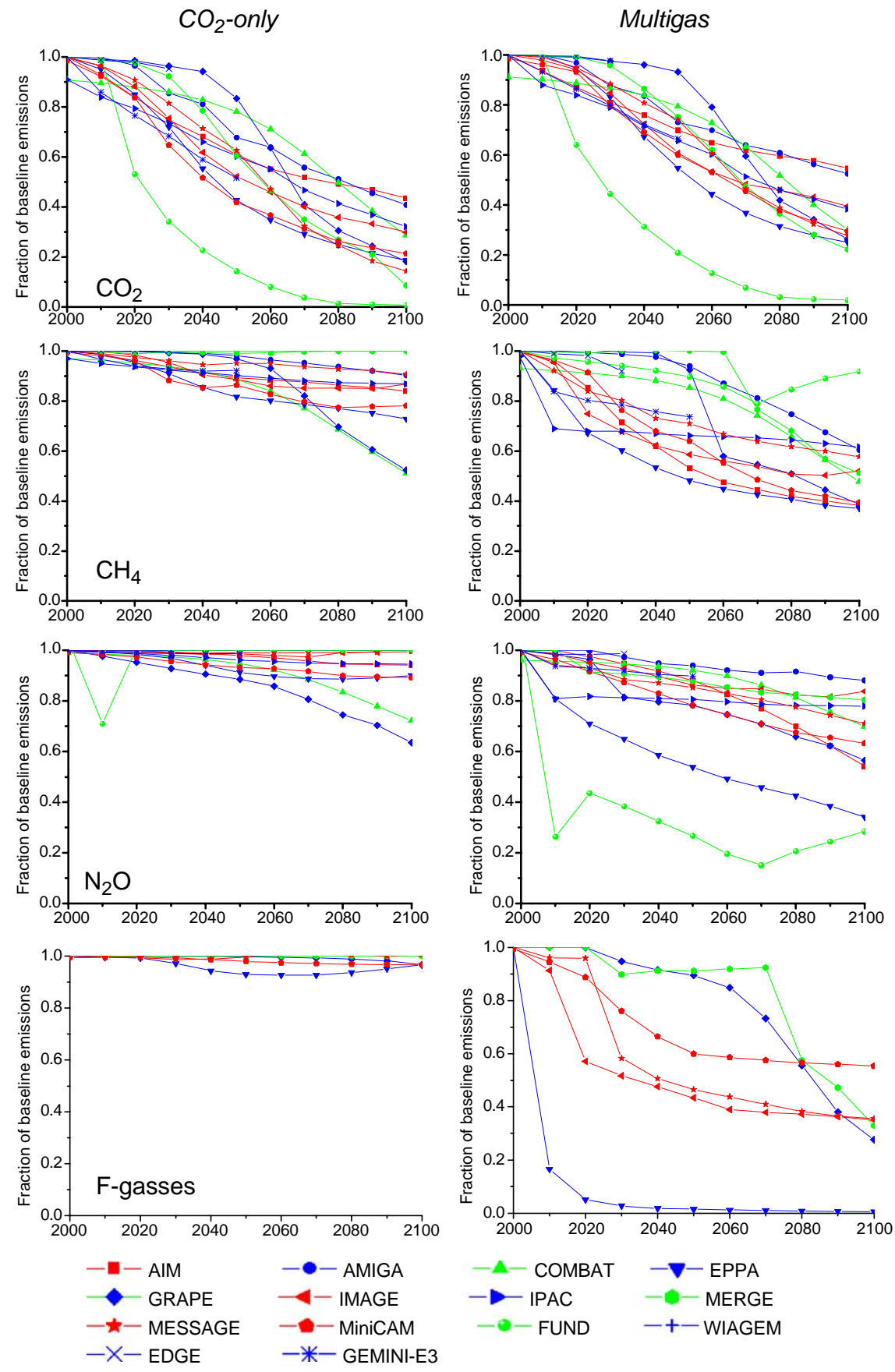

Fig. 5. Reduction of emissions in the $\mathrm{CO}_{2}$-only versus multi-gas strategies.

that, for $\mathrm{N}_{2} \mathrm{O}$, the use of GWPs versus direct contributions to radiative forcing as a way of weighing the contributions of the different gases to climate change does not make much difference because both gases have similar (medium length) lifetimes in the atmosphere. 
Table 3

Percentage reductions in greenhouse gases in $\mathrm{CO}_{2}$-only and Multi-Gas Control scenarios

\begin{tabular}{|c|c|c|c|c|c|c|c|c|c|}
\hline & \multirow{2}{*}{$\frac{\text { Reference }}{2100}$} & \multicolumn{4}{|c|}{$\mathrm{CO}_{2}$-only } & \multicolumn{4}{|c|}{ Multi-gas } \\
\hline & & Avg. & $-\mathrm{SD}$ & $+\mathrm{SD}$ & Red. (\%) & Avg. & $-\mathrm{SD}$ & $+\mathrm{SD}$ & Red. (\%) \\
\hline $\mathrm{CO}_{2}$ & 19.47 & 4.85 & 2.75 & 6.95 & 75 & 6.49 & 4.71 & 8.27 & 67 \\
\hline $\mathrm{CH}_{4}$ & 3.07 & 2.39 & 1.61 & 3.17 & 22 & 1.48 & 0.99 & 1.97 & 52 \\
\hline $\mathrm{N}_{2} \mathrm{O}$ & 1.23 & 1.11 & 0.54 & 1.68 & 10 & 0.77 & 0.60 & 0.93 & 38 \\
\hline F-gases & 0.83 & 0.82 & 0.49 & 1.17 & 2 & 0.22 & 0.09 & 0.35 & 73 \\
\hline Total & 24.62 & 9.18 & 7.13 & 11.23 & 63 & 8.95 & 7.22 & 10.68 & 64 \\
\hline
\end{tabular}

Emissions are reported in $\mathrm{CO}_{2}$ equivalence using 100-year GWPs.

\subsection{Costs of mitigation}

In the EMF-21 study, two concepts of costs were considered: the marginal costs of emission reduction and the reduction of GDP from a baseline scenario. Fig. 6 shows the ratio of marginal costs (i.e. the carbon tax used to induce the required emission reductions) in the multi-gas case to the $\mathrm{CO}_{2}$-only case. While there are clear differences among the models and in time, the reduction in the marginal costs amounts, on average, to $30-60 \%$. Almost all models show a much stronger reduction in the first decades, in which a considerable part of the more expensive emission reductions are now being replaced by cheaper reductions in NCGG emissions. The average reduction of the carbon tax in the first decades amounts to $50-60 \%$ across all models. In the second part of the century, the carbon tax is reduced by about $35-40 \%$ on average. Some models, however, again show an increasing cost benefit from the multi-gas strategy by the end of the scenario period as it avoids the steep cost increases involved in the deepest $\mathrm{CO}_{2}$ emission reductions.

For the second cost indicator, GDP losses, more or less the same results can be seen. The cost reduction here is about $30-40 \%$, with again the largest benefits occurring in the first decades of the scenario period. The slightly lower impact on GDP losses than on marginal reduction costs (carbon tax) is to be expected given the nature of the costs measures (the first measures marginal costs, while the second measure integrates across the whole range of measures taken). It should be noted that in both cases, however, impacts on costs are very substantial - certainly in comparison to the much smaller contribution of NCGGs to overall emissions.
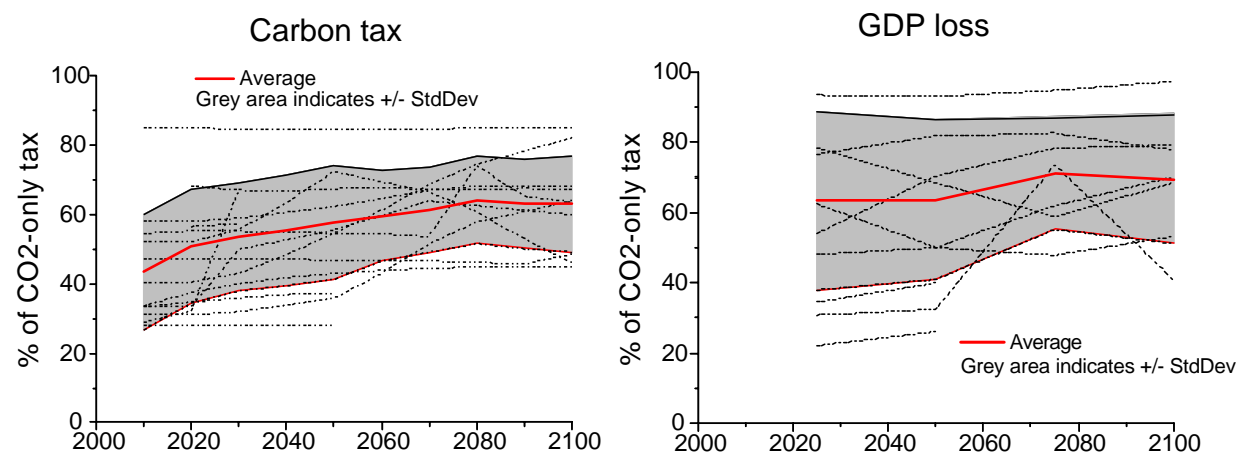

Fig. 6. Costs of stabilising radiative forcing at $4.5 \mathrm{~W} / \mathrm{m}^{2}$, ratio of costs in the multi-gas case to the $\mathrm{CO}_{2}$-only case (grey area indicates standard deviation). 


\section{Discussion on the metrics of multi-gas scenarios}

The previous sections have indicated the importance of considering multi-gas strategies as part of stabilization scenarios. In the introduction, however, we indicated that multi-gas strategies are more complicated than $\mathrm{CO}_{2}$-only strategies as they need metrics to compare the contribution of a set of gases with different lifetimes and different radiative properties. Such metrics are needed for two important issues (which some approaches combine into a single issue):

a. how to define the stabilization target for a multi-gas stabilization scenario and,

b. how to allow for substitution among the different greenhouse gases in a way that reflects their relative contributions to climate change.

In this section we will discuss some of the advantages and disadvantages of different targets and, where possible, use EMF-21 results to analyze them.

\subsection{Definition of stabilization target}

As the UNFCCC calls for a 'stabilization of greenhouse gas concentrations at a level that prevents dangerous anthropogenic interference' most mitigation studies have focused on stabilization scenarios. In the ' $\mathrm{CO}_{2}$-only' studies this meant stabilizing $\mathrm{CO}_{2}$ concentration. For multi-gas studies, one would need a similar long-term climate target but now integrating all of the NCGGs with $\mathrm{CO}_{2}$.

In general, a target for climate policy can be chosen anywhere in the causal change of climate change, as indicated in Fig. 7. Choosing a target early in the chain increases the certainty of required reduction measures (and thus costs), but decreases the certainty on climate impacts (see Fig. 7 and Table 4). Selecting a climate target further down the cause-effect chain (e.g.

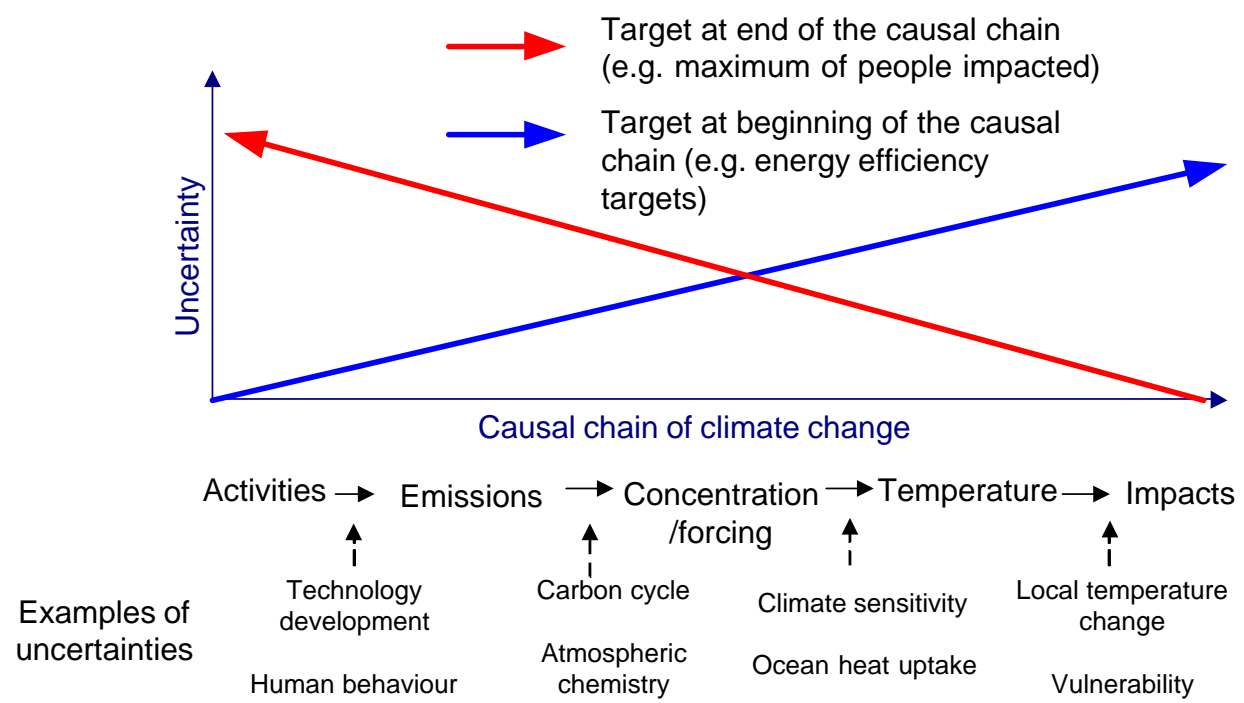

Fig. 7. Simple representation of the cause-effect chain of climate change. Choice of policy target within the chain has consequences for uncertainty. 
Table 4

Assessment of the main advantages of using different targets in modeling exercises, model comparison studies and assessment of available literature

\begin{tabular}{lll}
\hline Target & Advantages & Disadvantages \\
\hline Impacts & $\begin{array}{l}\text { Direct link to things climate policies aim } \\
\text { to avoid (direct link to Article 2, UNFCCC) }\end{array}$ & $\begin{array}{l}\text { Very large uncertainties in required } \\
\text { emission reductions and costs }\end{array}$ \\
Global mean temperature & $\begin{array}{l}\text { Metric is also used to organize impact } \\
\text { literature; and has shown to be a reasonable } \\
\text { proxy for impacts }\end{array}$ & $\begin{array}{l}\text { Large uncertainty on required emission } \\
\text { reduction (as result of the uncertainty }\end{array}$ \\
& $\begin{array}{l}\text { Relatively easy to translate to emission } \\
\text { targets (thus does not include climate }\end{array}$ & $\begin{array}{l}\text { Not as familiar as emissions or } \\
\text { Radiative forcing }\end{array}$ \\
& sensitivity in cost calculations) & terms of $\mathrm{CO}_{2}$-equivalent concentration) \\
& Allow for full flexibility in substitution & Cannot be directly observed or \\
& among gases & measured
\end{tabular}

Connects well to earlier work on $\mathrm{CO}_{2}$ stabilization

Allows for easy connection to work with GCMs/Climate models

Concentrations of separate greenhouse gases

Emissions

Can be translated relatively easily into emission profiles (reducing uncertainty on costs)

Lower uncertainty on costs
Does not allow for substitution among gases (thus losing the opportunities of cost reduction of 'What' flexibility) Very large uncertainty on global mean temperature increase and impacts Either needs a different metric to allow for aggregating different gases (e.g. GWPs) or forfeits opportunity of substitution

Costs/activities

Low uncertainty on direct abatement costs; relatively low uncertainty on macroeconomic costs

Rate of temperature increase Related to some forms of ecological impacts
Very large uncertainty on global mean temperature increase and impacts

Very high uncertainty on costs and probably unrealistic in early decades

temperature change, or even climate impacts avoided) increases certainty on impact reductions, but decreases certainty on required reduction measures (UNFCCC, 2002). In fact, uncertainties increase most (either way) in the step from radiative forcing to temperature change due to the large uncertainty range for climate sensitivity (Matthews and van Ypersele, 2003). Analogy with the $\mathrm{CO}_{2}$ concentration suggests formulating targets in terms of radiative forcing, which is equivalent to the concentrations of the different gases weighted by their radiative properties. The additional advantage of choosing radiative forcing targets over temperature targets is that for defining the required amount of the uncertainty caused by the unknown climate sensitivity does not play a role. The downside is, of course, that a wide range of temperature impacts is possible for the same radiative forcing level. Temperature targets have an important advantage of being more easily associated with impacts (which can be related somewhat to global temperature increase; as argued in the Third Assessment Report (IPCC, 2001).

In addition to long-term targets, short-term target also can be used, such as the maximum rate of temperature increase. In fact, several climate impacts could very well be related to climate change occurring to fast for ecosystems or human systems to adapt to. However, the little modeling done in EMF-21 on these targets suggest that in the first decades, stringent temperature rate targets can be difficult to comply too. In particular, MERGE calculations found that 
stringent temperature rate targets in the order of $0.2^{\circ}$ per decade can lead to high abatement costs (Manne and Richels, in press). Other models suggested similar results, by showing the high rate of temperature increase in their mitigation scenarios in the first decades, partly due to reduction of sulfate cooling in this period (e.g. (Van Vuuren et al., in press)). The implication is that if temperature rate targets are used, they need to be set carefully in the first decades.

The choice of the different targets is not only relevant because it leads to a different interpretation of (the same) uncertainty ranges. It is also relevant as it can lead to different strategies and outcomes. The clearest is that for those targets that forfeit the opportunity of substitution among gases such as concentration and emission targets by gas. But also the timing of emissions reduction may depend on the stabilization target chosen. If the aim is to stabilize temperature, it seems often economically more attractive to peak radiative forcing in a certain year, and next, to further reduce emissions to decrease radiative forcing levels instead of stabilizing radiative forcing directly. The former strategy can avoid the (delayed) further warming associated with the radiative forcing peak level, while still delaying some of the emission reductions in time and thus reducing discounted costs (see Elzen and Meinshausen, 2005).

The discussion in Table 4 concentrates on the selection of one particular target (e.g. for model comparison). In policy-making, however, a set of related targets will generally be chosen (instead of one single target) and this will be updated in time. For instance, the EU and several European countries have, as an ultimate target, decided on a maximum increase in global mean temperature of $2{ }^{\circ} \mathrm{C}$ compared to pre-industrial levels. This target is translated into related greenhouse gas concentration levels and then into emission reduction targets. In time, new insights in costs, climate sensitivity and/or impacts are likely to lead to re-evaluation of these targets. In this way, some of the disadvantages of certain targets, as indicated in Table 4, can be avoided.

\subsection{How to define substitution among gases}

For the second methodological question, a measure is needed by which the emissions of different greenhouse gases with different atmospheric lifetimes and different radiative properties can be compared. Ideally, such a measure would allow for substitution among different gases (in order to achieve cost reductions) but ensures equivalence in climate impact. Fuglestvedt et al. (2003) provides a comprehensive overview of the different methods proposed, and the advantages and disadvantages of using them. One of these, $\mathrm{CO}_{2}$-equivalent emissions based on the Global Warming Potentials (GWP), has been adopted in most current climate policies, such as the Kyoto Protocol and US climate policy (White-House, 2002). While the use of GWPs is often regarded as simply being convenient, there has also been a continuous debate on the use of them for this purpose, based on both natural science and economic arguments. These include the point that GWPs do not account for the economic dimension of the problem and, are based on a rather arbitrary time horizons. Other substitution metrics have been proposed as well. Intertemporal optimization models that include radiative forcing and climate change equations can, in fact, totally avoid the use of substitutions metrics such as GWPs by simply optimizing across the different gases under the long-term target as shown within EMF-21.

The question of how to substitute among different gases over time is not independent of the policy target discussed in the previous section. If only long-term targets are selected, the costoptimal strategies from the intertemporal optimization models will-early on-not focus on reducing short-lived gases. Manne and Richels (2001) showed that for, meeting long-term 


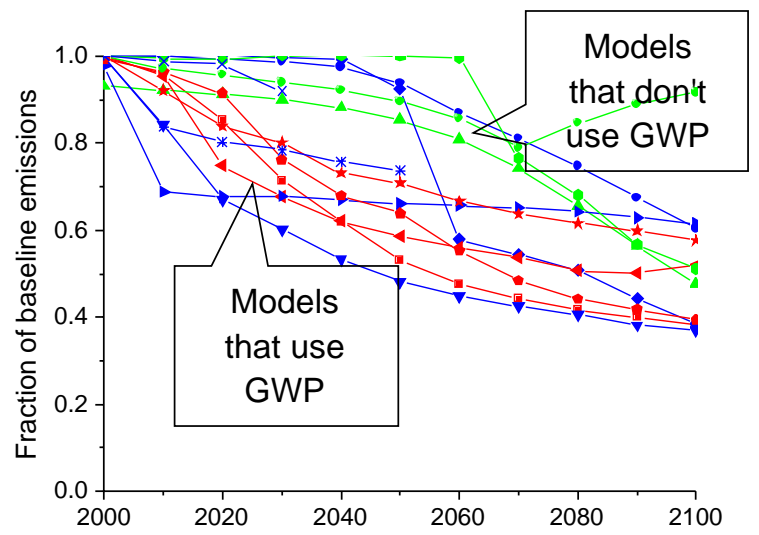

Fig. 8. Reduction of methane for models that use year-by-year fixed (GWPs) or those that base substitution on intertemporal optimization.

targets reducing methane early in the scenario period does not lead to any result given its short lifetime. This can be well illustrated by the comparison study performed in EMF-21. Figs. 8 and 9 show the reduction rates over time again for methane, aiming at stabilization of radiative forcing at $4.5 \mathrm{~W} / \mathrm{m}^{2}$ using a multi-gas approach. While most models based substitution on using GWPs, four models in contrast based substitution on direct contributions to radiative forcing within a full inter-temporal economic optimization framework. The last four are indicated in green in Fig. 8. While for most gases, there are no clear differences among the two groups, for methane there is a very clear difference. For those models that base substitution on GWPs, the reduction of $\mathrm{CH}_{4}$ emissions in the first three decades is already substantial. In contrast, models that do not use GWPs only start to reduce $\mathrm{CH}_{4}$ substantially by the end of the period. The logic in the latter case is that aiming specifically on the long-term target set in the analysis, early $\mathrm{CH}_{4}$ reduction does not pay off given its short lifetime. In the first group of models, however, $\mathrm{CH}_{4}$ emissions are attractive on the basis of the available low-cost reduction options. This is illustrated too in Fig. 9, where a direct comparison is seen between IMAGE (based on GWPs)

IMAGE

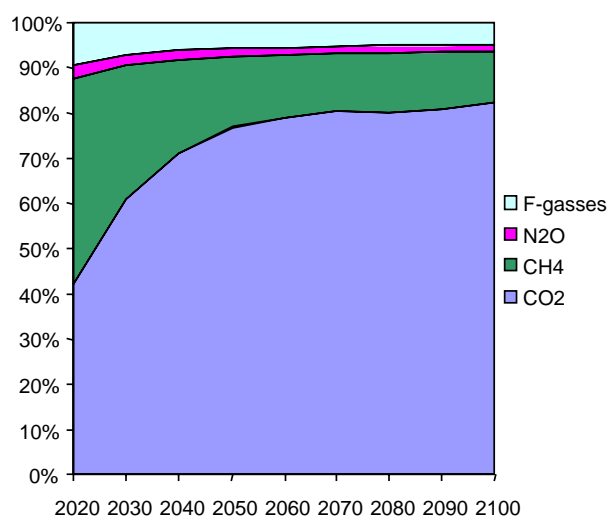

MERGE

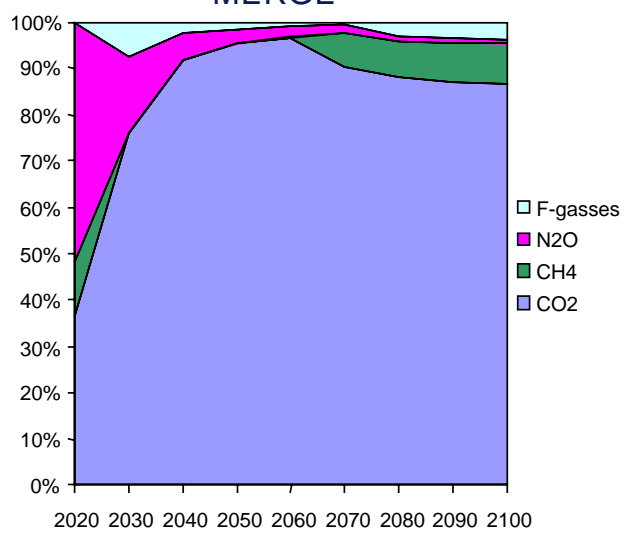

Fig. 9. Contribution of different gases in overall reductions. Comparison of a model using GWPs as the basis of substitution (IMAGE) to a model using inter-temporal optimization (MERGE). 
and MERGE (based on contributions to radiative forcing within an inter-temporal costoptimization framework) results. In IMAGE, a very substantial share of reductions is obtained from $\mathrm{CH}_{4}$ and the F-gases in the early periods. Their share declines over time (as cheap reduction options are exhausted). MERGE in contrast shows almost no reduction in methane emissions until 2070. $\mathrm{N}_{2} \mathrm{O}$ in contrast represents a major share of early reductions. Finally, by 2100 there is not much difference between the two approaches.

What do these results imply for policy-making? For policy-making purposes, a substitution metric should not only be operational in a modeling context, but also in the real world. The cost reductions from a multi-strategy shown Section 4 can only be achieved if substitution metrics are available that are acceptable to a large group of actors involved in climate policy. As alternative to the GWPs that are now used as substitution metric, it is, in principle, possible to derive the 'exchange rates' of different gases from model results of the cost-optimizing models, as shown by Manne and Richels (2001). However, there are two complications. First, these alternative metrics are model dependent (e.g. the current insights into present and future mitigation costs) and (by definition) dependent on the target that is chosen in the analysis. As uncertainties on costs add to those on radiative forcing, these alternative exchanges rates are more uncertain and require a debate on the correct economic model and mitigation potentials. The second complication is that for multi-gas emission reduction strategies and multi-gas trading markets to function correctly, the changes in the value of the exchange rate over time (if any) need to be predictable and smooth. Otherwise, the additional risk of changes in the exchange rate could prevent investors from making otherwise cost-optimal investments. Given the dependency on models and mitigation costs, fully cost-optimal metrics might not be able to pass this test. Relevant questions are therefore (1) what are the additional costs of using GWPs versus not using them (are the costs if using GWPs as metric close enough to the lowest costs achievable); and (2) can other 'real world' metrics (that do comply with the considerations above) be developed that have a better performance. Several studies, (O’Neill, 2003; Aaheim et al., in press; Person et al., 2004), have argued that the disadvantages of GWPs are likely to be outweighed by their advantages by showing that the cost difference between a multi-gas and $\mathrm{CO}_{2}$-only strategy is much larger than between a GWP-based multi-gas strategy and a costoptimal strategy (thus suggesting that GWPs can achieve most of the cost savings).

One should also note that the cost-optimal results as discussed here are fully optimized under a long-term target, with no benefits assigned to short-term benefits, such as a lower rate of temperature change. This assumption leads to much more extreme differences between the costoptimization and GWP-based strategies than alternative analyses that would have valued shortterm gains as well. As GWPs are calculated on the basis of the integral of radiative forcing throughout the century, they automatically give some value to short-term benefits. Strategies with GWP-based substitution (or cost-optimal results based on temperature rate targets) lead to significantly less warming throughout the scenario period achieved by considerable reductions of $\mathrm{CH}_{4}$ early in the scenario period. Postponing this abatement (as suggested by flexible optimization) leads to higher rates of temperature in the first few decades. Thus, a relevant question within the debate on metric is whether climate policy should focus on long-term targets only, or also on short-term targets such as the rate of temperature change.

The discussion above indicates that the discussion on useful substitution metrics is still open - and that some messages start to emerge from this debate. It would seem very appropriate to reconsider the use of GWPs as substitution metric in the light of the debate on costs and benefits (and not only in the light of their physical properties as has been the focus of the debate on GWPs up to now). The results of such evaluation are not clear yet - and would focus on the 
costs of using GWPs versus ideal metrics, but also their ability to make a multi-gas strategy feasible in the real world.

\section{Conclusions and the way forward}

EMF-21 performed a multi-model comparison project on scenarios that not only encompass $\mathrm{CO}_{2}$, but also other major greenhouse gases. The analysis showed the following results:

- Under baseline conditions, emissions of non- $\mathrm{CO}_{2}$ gases are expected to grow considerably from around $2.7 \mathrm{GtC}$-eq/year in 2000 to $5.1 \mathrm{GtC}$-eq/year in 2100 (average across all models; standard deviation range of 3.2-7.1 GtC-eq/year). Despite this emission increase, the share of non- $\mathrm{CO}_{2}$ gases is expected to be reduced from $29 \%$ to $21 \%$. Both $\mathrm{CH}_{4}$ and $\mathrm{N}_{2} \mathrm{O}$ are expected to grow slower than $\mathrm{CO}_{2}$, as their emissions mainly originate from agricultural activities (growing less rapidly than the main driver of $\mathrm{CO}_{2}$ emissions, energy use). Emissions of the group of F-gases are expected to grow considerably faster than $\mathrm{CO}_{2}$.

- A multi-gas strategy can achieve the same climate goal at considerably lower costs than a $\mathrm{CO}_{2}$-only strategy. The cost reduction may amount to about $30-40 \%$ for GDP losses and 35$60 \%$ for the marginal abatement costs. The largest cost reductions are expected to occur early on in the mitigation policy.

- The use of different metrics to aggregate and compare different greenhouse gases (either for the stabilization target or for substitution) plays a crucial role in the final results of a multi-gas strategy. More analysis and assessment (for instance, by IPCC) could help to further develop insights into the consequences of selecting certain metrics. This is very important for both research and policy-making.

- The crucial impact of substitution metrics for multi-gas strategies can be directly seen in the EMF-21 results. Under a multi-gas strategy using the 100-year GWPs, the contribution of the non- $\mathrm{CO}_{2}$ gases in total reductions is very large early in the scenario period $(50-60 \%$ in the first two decades). Later in the scenario period, the contribution of most gases becomes more proportional to their share in baseline emissions. Not using GWPs, but determining substitution on the basis of cost-effectiveness instead to realize a long-term target within models, implies that reductions in $\mathrm{CH}_{4}$ are delayed to later in the century.

- Regarding the stabilization target (the second metric), EMF-21 analysis has focused on stabilizing radiative forcing. However, some publications have indicated that stabilization of global temperature can be achieved more cost-effectively through profiles that result in radiative forcing levels that peak and then decline. Further research could focus on such overshoot scenarios.

- Identified reduction potentials for non- $\mathrm{CO}_{2}$ gases become exhausted if substantial emission reductions are required, for instance, reductions to $40 \%$ for $\mathrm{N}_{2} \mathrm{O}$ compared to baseline across all models and to $50 \%$ for $\mathrm{CH}_{4}$ (compared to almost $70 \%$ for $\mathrm{CO}_{2}$ ). Further research into identifying means to reduce agricultural $\mathrm{CH}_{4}$ and $\mathrm{N}_{2} \mathrm{O}$ emissions and expected technological change is therefore an important research topic.

\section{References}

Aaheim, H.A., Fuglestvedt, J.S., Godal, O., in press. Costs savings of a flexible multi-gas climate policy. The Energy Journal.

Blok, K., De Jager, D., Hendriks, C., 2001. Economic Evaluation of Sectoral Emission Reduction Objectives for Climate Change-Summary Report for Policy Makers. Ecofys Energy and Environment, Utrecht, The Netherlands. 
Delhotal, K.C., Gallaher, M., 2005. Estimating technical change and potential diffusion of methane abatement technologies for the coal-mining, natural gas and landfill sectors. IPCC Expert Meeting on Industrial Technology Development, Transfer and Diffusion. Conference proceedings. IPCC Working Group III Technical Support Unit, Bilthoven, The Netherlands.

Elzen, M.G.J., Meinshausen, M., 2005. Meeting the EU 2 Degree Target: Global and Regional Emission Implications. RIVM, Bilthoven, The Netherlands.

EMF, 2005. Stanford Energy Modeling Forum EMF-21. http://www.stanford.edu/group/EMF/home/index.htm.

Fuglestvedt, J.S., Berntsen, T.K., Godal, O., Sausen, R., Shine, K.P., Skodvin, T., 2003. Metrics of climate change: assessing radiative forcing and emission indices. Climatic Change 58, 267-331.

Graus, W., Harmelink, M., Hendriks, C., 2004. Marginal GHG-Abatement Curves for Agriculture. Ecofys, Utrecht.

Hansen, J., Sato, M., Ruedy, R., Lacis, A., Oinas, V., 2000. Global warming in the twenty-first century: An alternative scenario. PNAS 18 (97), 9875-9880.

Hayhoe, K., Jain, A., Pitcher, H., MacCracken, C., Gibbs, M., Wuebbles, D., Harvey, R., Kruger, D., 1999. Costs of multigreenhouse gas reduction targets for the USA. Science 286, 905-906.

Hourcade, J.C., Shukla, P., 2001. Global, regional and national costs and ancillary benefits of mitigation. In: Metz, B., Davidson, O., Swart, R., Pan, J. (Eds.), Climate Change 2001: Mitigation. Cambridge University Press, Cambridge.

IPCC, 2001. In: Houghton, J.T., Ding, Y., Griggs, D.J., Noguer, M., van der Linden, P.J., Xiaosu, D. (Eds.), Climate Change 2001: The Scientific Basis. Contribution of Working Group I to the Third Assessment Report of the Intergovernmental Panel on Climate Change. Cambridge University Press, United Kingdom.

Jensen, J., Thelle, M., 2001. What are the Gains from a Multi-Gas Strategy? Fondazione Eni Enrico Mattei, Milano, Italy.

Manne, A.S., Richels, R.G., 2001. An alternative approach to establishing trade-offs among greenhouse gasses. Nature 5, $675-677$.

Manne, A.S., Richels, R.G., in press. The role of non-CO2 greenhouse gasses and carbon sinks in meeting climate objectives. The Energy Journal.

Matthews, B.J.H., van Ypersele, J.P., 2003. UNFCCC Article 2, stabilisation and uncertainty: engaging citizens with a web-based climate model. http://www.chooseclimate.org/.

Nakicenovic, et al., 2000. Special Report on Emissions Scenarios (SRES). Cambridge University Press, Cambridge, UK.

O’Neill, B.C., 2003. Economics, natural science and the costs of global warming potentials. Climatic Change 58, $251-260$.

Person, U.M., Johansson, D.J., Azar, C., 2004. Integrated Assessment of the Economic Trade-Off $\mathrm{Between}^{\mathrm{CO}_{2}}, \mathrm{CH}_{4}$ and $\mathrm{N}_{2} \mathrm{O}$ Abatement-Efficiency Losses from Using Static GWPs.

Reilly, J., Prinn, R., Harnisch, J., Fitzmaurice, J., Jacoby, H., Kicklighter, D., Melillo, J., Stone, P., Sokolov, A., Wang, C., 1999. Multi-gas assessment of the Kyoto Protocol. Nature 401, 549-555.

Tol, R.S.J., 1999. The marginal costs of greenhouse gas emissions. Energy Journal 20 (1), $61-81$.

UNFCCC, 2002. Methodological Issues, Scientific and methodological assessment of contributions to climate change, Report of the expert meeting, Note by the secretariat, FCCC/SBSTA/2002/INF.14 (http:/www.unfccc.int).

USEPA, 1999. U.S. Methane Emissions 1990-2020: Inventories, Projections, and Opportunities for Reductions. USEPA, Washington, DC. (http://www.epa.gov/methane).

Van Vuuren, D.P., Den Elzen, M.G., Berk, M.M., Lucas, P.L., Eickhout, B., Eerens, H., Oostenrijk, R., 2003. Regional Costs and Benefits of Alternative Post-Kyoto Climate Regimes. National Institute for Public Health and the Environment, Bilthoven, The Netherlands.

Van Vuuren, D.P., Eickhout, B., Lucas, P., Den Elzen, M.G.J., in press. Long-term multi-gas scenarios to stabilise radiative forcing- exploring costs and benefits within an integrated assessment framework. The Energy Journal.

Weyant, J.P., De la Chesnaye, F.C., Blanford, G.J., 2005. Overview of EMF-21: Multigas mitigation and climate change. Energy Journal.

White-House, 2002. Executive Summary of Bush Climate Change Initiative.

Wigley, T.M.L., Raper, S.C.B., 2001. Interpretation of high projections for global-mean warming. Science 293, $451-454$. 